\title{
Gênero, arte e educação: resistências e novas paisagens do possível
}

\author{
LUCIANA GRUPPELLI LOPONTE \\ UNIVERSIDADE FEDERAL DO RIO GRANDE DO SUL
}

\section{Resumo}

$\mathrm{O}$ artigo revisita alguns argumentos sobre a relação entre gênero, imagens e arte, especialmente no que se refere às representações de imagens femininas no campo das artes visuais no ocidente e a perpetuação da naturalização da violência sexual e da submissão do corpo da mulher a certo olhar contemplativo masculino. A discussão apresentada é atravessada pelos acontecimentos de 2017 no Brasil, quando a exposição "Queermuseu: cartografias da diferença na arte brasileira" foi subitamente encerrada, e atualizada em 2020 quando, em meio a uma das maiores pandemias do século, os índices de violência contra mulheres aumentam vertiginosamente. Que imagens são necessárias para o nosso tempo? Quais as ressonâncias necessárias desse debate no campo da arte e da educação? Este texto inscreve-se nesse propósito, pretendendo agregar mais argumentos para a urgência do debate, necessariamente coletivo.

Palavras-chave: gênero; violência de gênero; artes visuais; educação; resistências.

\section{Abstract}

The paper revisits some arguments about the relation between gender, images and art, especially regarding the representations of feminine images in the field of visual arts in the occident and the perpetuation of the naturalization of sexual violence and the submission of the woman body to a given masculine contemplative. The discussion presented is traversed by the happenings of 2017 in

17 Doutora em Educação, professora da Faculdade de Educação da Universidade Federal do Rio Grande do Sul. E-mail: luciana.arte@gmail.com 
Brazil, when the exposition "Queer museum: cartographies about difference in brazilian arts", was suddenly finished and updated in 2020 when, in the middle of one of the greatest pandemics of the century, the rates of violence against women rose vertiginously. Which images are necessary for our time? What are the resonances needed from this debate in the field of art and education? This text is inserted in this purpose, aiming to aggregate more arguments for the urgency of the debate, necessarily collective.

Key-words: gender; gender violence; visual arts; educations, resistances

Já há alguns anos tenho escrito, pensado e pesquisado sobre gênero, arte e educação. A preocupação com essa temática começou em uma professora de arte inquieta com a ausência dessas questões nas discussões vigentes sobre ensino de arte no Brasil, em meados da década de 90. Desde então, tenho pesquisado e publicado artigos (LOPONTE, 2005; 2010; 2015 e outros) e orientado pesquisas sobre a temática (COUTINHO, LOPONTE, 2015; DIAS, 2017; VELOSO, 2019). Nesses escritos, tenho insistido na necessidade da inserção de temas mais políticos na discussão sobre o ensino de arte, envolvendo relações de gênero e suas relações de poder. Como afirmei em um desses artigos, e continuo insistindo, acredito que o campo de estudos que envolve arte e educação tem muito a aprender com os debates contemporâneos sobre gênero e sexualidade: "Compreender que a arte (artes visuais, teatro, música e dança) e sua aparente 'inocência' contribuem para a perpetuação de sexismos e a naturalização do 'intolerável', é uma das lições mais urgentes" (LOPONTE, 2010, p. 160).

Quando escrevemos e espalhamos nossas palavras por aí, nunca sabemos onde elas podem chegar. Quando comecei a pesquisar sobre esses temas nos anos 90, essa discussão no Brasil ainda era muito incipiente. Muita coisa mudou desde então, novas pesquisas surgiram, novos estudos foram publicados, ainda que não suficientemente levados em conta, principalmente no campo da arte e educação. Alguns anos atrás, recebi um e-mail de uma pesquisadora de São Paulo que, com seus 25 anos de idade, afirmava ter se inspirado em um artigo meu para fazer sua monografia de especialização sobre mulheres na história da arte. Continuo recebendo mensagens desse tipo, por vários meios. Sim, nossas palavras chegam longe, circulam e provocam novas ideias, mesmo depois de um tempo. Esse e-mail, além de ser um alento, fez-me pensar que há uma nova geração de pesquisadores e pesquisadoras surgindo, preocupada com temáticas feministas relacionadas às artes e às relações entre gênero, sexualidade e as artes. E, paradoxalmente, isso está acontecendo ao mesmo tempo em que uma onda neoconservadora passa a ter mais força no pensamento político brasileiro, provocando distorções que aca- 
baram praticamente banindo a palavra gênero do Plano Nacional de Educação e da Base Nacional Comum Curricular. É neste mesmo tempo em que emerge uma nova geração feminista e de luta pelos direitos de gays, lésbicas, transexuais e travestis, que vemos exposições de arte sendo atacadas por grupos moralistas, que testemunhamos teóricas feministas sendo ameaçadas de serem queimadas em praça pública ${ }^{18}$. Tudo está acontecendo agora, neste mesmo instante. E precisamos nos posicionar, nos informar, pensar além dos clichês e dos jargões, desconstruir preconceitos, desmontar verdades aparentemente imutáveis, inventar novos modos de resistência. Urgência é a palavra.

É a partir desse contexto e com o empenho dessa urgência, que faço a minha contribuição. Neste texto, revisito alguns argumentos sobre a relação entre gênero, imagens e arte, pensando especialmente o quanto as representações de imagens femininas no campo das artes visuais no ocidente perpetuaram por muito tempo e ainda perpetuam a naturalização da violência sexual e da submissão do corpo da mulher a certo olhar contemplativo masculino. É importante ressaltar ainda a manutenção de clichês de feminilidade nas imagens artísticas que, de algum modo, acabaram milenarmente configurando o nosso olhar para nós mesmas e para outras mulheres (e, certamente, construindo também masculinidades). Ainda que este seja um tema muito debatido, especialmente pela crítica feminista de arte (MAYAYO, 2003; POLLOCK, 1998; BARROS, 2016), ainda há muito para ser dito, principalmente considerando o quanto, muitas vezes, prevalece um enfoque formalista no campo da arte, um campo considerado autônomo e descompromissado das relações mundanas e sociais da vida cotidiana. Penso também ser importante que tomemos contato com produções artísticas que, de algum modo, propõem um deslocamento desse olhar mais naturalizado para imagens femininas, instigando um pensamento que vai muito além de qualquer tipo de vitimismo ou denuncismo, mas que inscreva essas imagens em um jogo de relações de poder e resistência.

A discussão aqui apresentada é atravessada também pelos acontecimentos do ano de 2017 no Brasil ${ }^{19}$, envolvendo um súbito interesse da opinião pública

18 A respeito desses eventos acontecidos no ano de 2017 no Brasil, ver as notícias do fechamento da exposição Queermuseu em Porto Alegre: https://brasil.elpais.com/brasil/2017/09/11/politica/1505164425_555164. html e a reação conservadora a vinda da intelectual feminista e queer Judith Butler ao Brasil: http://www. jb.com.br/pais/noticias/2017/11/10/filosofa-americana-judith-butler-e-alvo-de-protestos-no-aeroporto-de-congonhas/

19 Os desdobramentos e efeitos desses eventos continuaram reverberando nos anos posteriores, sendo decisivos nas eleições gerais realizadas em 2018 no Brasil (para presidente, governadores dos estados, deputados e senadores) e, em 2020, quando atravessamos uma das maiores pandemias do século, efeito da contaminação pelo vírus COVID 19. 
por exposições e museus de arte que, de locais frequentados por poucos curiosos e especialistas, passaram a ser consideradas como locais de perversão infantil, pornografia explícita e destruição dos valores éticos e sagrados da "família brasileira". O debate gerado pelo fechamento da exposição "Queermuseu: cartografias da diferença na arte brasileira" no Santander Cultural, em Porto Alegre, em setembro de 2017, teve muitos efeitos políticos, sociais e culturais, os quais ainda não dimensionamos de forma suficiente e que, definitivamente, não podem ficar de fora de um texto que pretende tratar justamente de gênero, imagens, arte, poder e resistência. Neste artigo, o debate é atualizado para o ano de 2020, em que o mundo é abalado por uma das maiores pandemias do século e os índices de violência contra as mulheres aumentam vertiginosamente. A urgência do tema atravessa este texto de forma incontornável. Que imagens são necessárias para o nosso tempo? De que modo as imagens permitem-nos continuar pensando além da superficialidade de interpretações rasas e apressadas? Quais as ressonâncias necessárias desse debate no campo da arte e da educação? A tarefa é imensa e não se faz de modo solitário. Este texto inscreve-se nesse propósito, pretendendo agregar mais argumentos para a urgência do debate, necessariamente coletivo.

\section{Imagens, arte e violência de gêenero}

Sob o signo linguístico mulher ou feminino, há muitas possibilidades e experiências dificilmente traduzidas por essas palavras. Através de um conjunto de imagens do que podemos considerar arte ocidental mainstream, fomos fartamente representadas, olhadas, seduzidas, imaginadas, fetichizadas. Este é um tema recorrente entre pesquisadoras feministas ligadas ao campo da arte a partir dos anos 70. Muitas dessas intervenções feministas, como chamou Pollock (1988), "contribuem de alguma maneira para que nosso olhar perca a inocência e cada vez mais desconfie de uma suposta neutralidade política das imagens" (LOPONTE, 2010, p. 156)". Mayayo sublinha o quanto a análise de "imagens de mulheres" teve crucial importância no âmbito da crítica feminista, especialmente para contribuir com a ruptura do "mito da neutralidade das imagens artísticas" (MAYAYO, 2003, p. 165):

$\mathrm{O}$ que os artistas e historiadores de arte tenderam a apresentar muitas vezes como valores universais e absolutos (por exemplo, certas concepções de beleza e de erotismo) reflete em realidade um ponto de vista muito concreto: o do homem ocidental, de raça branca e de classe média; na história do Ocidente, o masculino se transformou na norma do genérico humano (MAYAYO, 2003, p.165). 
Destaco, para este texto, algumas imagens artísticas ocidentais (marcadamente europeias) que, de algum modo, naturalizam a violência sexual contra as mulheres. Nos livros clássicos de história de arte - essa "lenda canônica da criatividade cristã masculina ocidental” (POLLOCK, 1988, p. XIX) -, tal violência é obscurecida por leituras formalistas que enfatizam a ousadia visual dos artistas (homens, em sua grande maioria) e salientam aspectos como uso da cor, contraste entre luz e sombra, volume e movimento, genialidade da composição. Por muito tempo, como estudante de arte e aprendiz desse tipo de discurso, não conseguia enxergar além desse tipo de interpretação. Vemos tal como aprendemos a olhar. Afinal, podíamos pensar, as mulheres estavam lá, em profusão, recheando as imagens dos grossos livros de verdades sobre a história da arte. O que haveria de mal nisso? Fugindo de qualquer oposição binária, não se trata obviamente de bem ou mal, ou de boas ou más imagens de mulheres, mas de como aprendemos a nos ver, homens e mulheres, em um espelho que nos refletiu insistentemente como objetos de um determinado olhar, não como sujeitos ou protagonistas. Os efeitos desse modo de subjetivação milenar são incalculáveis, incluindo as meninas e meninos que conhecem imagens de arte em escolas ou através da cultura visual do cotidiano.

Como exemplos, podemos analisar mais de perto imagens recorrentes de raptos e sequestros, cujo desfecho em estupros e violações é claramente (ou não) subtendido: O rapto das filhas de Leocipo (1615-1618), de Rubens, ou o Rapto das Sabinas de Giovanni Bologna, ou as inúmeras versões de A Susana e os velhos. Um contraponto a essas imagens de violação sobre essa temática é a extemporânea obra de Artemísia Gentileschi, do período barroco italiano, artista frequentemente citada pela crítica feminista da história da arte. Nessas imagens, entram em jogo situações dúbias de violação e consentimento, prazer sexual masculino e objetificação da sexualidade feminina. Podemos considerar também o "fenômeno da mulher reclinada", uma das tipologias iconográficas da modernidade, como uma forma de violência, conforme aponta Aliaga (2010):

Nada há, por conseguinte, de bom ou mau, de positivo ou de negativo em uma figura de mulher sem roupa recostada em um divã, mas no momento em que, a partir de um aparato conceitual e epistemológico mais global, se tem em conta o trato social discriminatório e degradante que sofreu a população feminina ao largo da história, com suas variantes e mudanças, o prisma com que se analisa essa imagem de mulher adquire conotações sem dúvida violentas (ALIAGA, 2010, p. 32). 
Sobre o modernismo nas artes visuais, em especial na Europa, é marcante que a maioria das obras considerada cânone da fundação da chamada arte moderna remetam à sexualidade, como anota Pollock (2011, p. 57): “devemos questionar por que razão o território da modernidade é tão frequentemente uma forma de lidar com a sexualidade masculina e com os corpos de mulheres - porquê a nudez, o bordel, o bar? Qual é a relação entre sexualidade, modernidade e modernismo?". Nas imagens coroadas e celebradas da história da arte moderna ocidental, vemos bailarinas, banhistas, mulheres se vestindo, mulheres em bares, nus femininos em profusão. Mas quem eram essas mulheres que frequentavam os espaços públicos no início do século XX? Havia claramente uma divisão de classes e gêneros em jogo: a sexualidade masculina permitida e uma sexualidade feminina objeto de troca comercial. A maioria das mulheres não tinha o direito de olhar, observar, examinar, entendidas "como objeto de olhar do flâneur" (POLLOCK, 2011, p. 59), fazendo uma alusão ao célebre texto de Baudelaire.

O modo de olhar instaurado no modernismo, caracterizado, entre outros aspectos, pelo seu formalismo, ahistoricismo, linguagem visual extrema e reverência à figura individualista do artista, acaba fomentando discursos que persistem até hoje, inclusive no ensino de arte, que destacam "uma concepção de arte entendida como expressão individual, margeando a necessária reflexão social e a inserção na coletividade" (ALIAGA, 2010, p. 32). Aliaga salienta, no entanto, o quanto a crítica feminista da arte abre outras possibilidades de pensamento:

\begin{abstract}
Em um polo intelectual oposto, o feminismo aporta, entre muitas outras coisas, uma via epistemológica que serve de freio a arte contemplativa, cujos objetivos ensimesmados buscavam defender valores universais ao mesmo tempo que transcendentes (com o pretexto de não cair nas realidades sociais prosaicas). Essa visão modernista da arte como matéria autônoma, com seu próprio credo, inerente a argamassa estética, desgarrada das circunstâncias sociais de sua produção e circulação, foi enormemente influente. E se expandiu por cátedras universitárias, faculdades de Belas Artes, revistas e publicações, galerias, centros e museus, meios de comunicação, internet, o mercado (ALIAGA, 2010, p.15).
\end{abstract}

Neste texto, o que vale ser destacado é o quanto a violência de gênero - entendida como aquela que "põe em perigo os direitos fundamentais, a liberdade individual e a integridade física das mulheres" 20 - também está presente de formas

20 A Declaração e Plataforma de Ação de Beijing, aprovada na quarta Conferência Mundial das Mulheres, realizada em Pequim, em 1995, define que: “A expressão 'violência contra a mulher' se refere a todo ato de violência baseado em gênero que tem como resultado possível ou real um dano físico, sexual ou psicológico, 
sutis (ou não) na aparente superfície neutra das imagens artísticas, subjetivando nossos modos de estar no mundo. É nessa direção que Aliaga (2010) sustenta que estamos, em alguma medida, sujeitos a estratégias de poder de ordem fálica. Distante de qualquer "cultura da queixa" ou de vitimismo, como faz questão de destacar o autor, a intenção é demonstrar, através de algumas imagens, o quanto a violência de gênero permeia vários discursos do campo da arte, mesmo aqueles canonizados e sacralizados pela História da Arte em maiúsculas. Escrutinar e esmiuçar tais estratégias de poder-saber é, de algum modo, produzir modos de resistência.

Se as imagens nos constituem, o que dizer sobre a interdição de imagens? De que modo imagens proibidas constituem nossos desejos?

\section{Sobre uma exposição não vista: as imagens intole- ráveis do Queermuseu}

As artes visuais, especialmente a partir de certo pensamento de senso comum, e, apesar de tudo que já foi produzido e pensado milenarmente, continuam apegadas a sua tradição mimética. Supõe-se, como nos lembra Rancière, na sua crítica a determinadas políticas da arte, que "a arte nos torna revoltados quando nos mostra coisas revoltantes", apresentando-se como evidente "a passagem da causa ao efeito, da intenção ao resultado" (RANCIÈRE, 2012, p.52). Neste sentido, a imagem nos contagiaria, nos moveria a determinada ação imediata? Como um vírus, as imagens nos contaminariam de forma incontrolável a tal ponto que seríamos capazes de fazer coisas completamente impensadas?

Ainda que possam parecer ingênuas tais indagações, considerando o repertório de imagens produzidas, pensadas e consumidas em pleno século XXI, é no cerne dessas discussões que assistimos, estupefatos, aos acontecimentos da cena cultural no Brasil de 2017, quando exposições e ações artísticas foram atacadas violentamente por uma onda moralista e conservadora que aliou de forma perversa discursos sobre infância, arte, gênero e sexualidade (CULT, 2017; CYPRIANO, 2018). Pontualmente, vimos a exposição "QueerMuseu: cartografias da diferença na arte brasileira”, com curadoria de Gaudencio Fidelis, prevista para acontecer no Santander Cultural, em Porto Alegre, de 15 de agosto a 8 de outu-

incluídas as ameaças, a coerção ou a privação arbitrária da liberdade, quer seja na vida pública ou na vida privada". Disponível em: http://www.un.org/womenwatch/daw/beijing/pdf/BDPfA\%20S.pdf Acesso em 14 de maio de 2018. 
bro de 2017, ser sumariamente fechada um mês antes, por conta das difamações sofridas pelas redes sociais e no próprio espaço do museu (CULT, 2017). A exposição foi acusada de promover pedofilia, zoofilia, pornografia gratuita e ofensa religiosa, sendo capaz de corromper a infância e juventude, além de macular de forma condenável credos religiosos. De forma violenta, qualquer pessoa que manifestasse publicamente nas redes sociais apoio à instituição ou à exposição era acusada de ser pedófila ou praticar zoofilia. Há uma trama intrincada de questões em jogo nesse acontecimento e que envolve uma ação política coordenada de alguns grupos, que encontrou, na defesa por certa moralidade uma causa de fácil e passional, adesão de um público mais suscetível. Além disso, poderíamos incluir, no contexto dessa situação, um jogo político polarizado no país, uma democracia frágil, crise econômica, a ascensão de pautas conservadoras e fundamentalistas no poder legislativo em várias instâncias, a identificação pejorativa da defesa de direitos humanos, das diferenças, da arte e da cultura como pautas de uma determinada esquerda ${ }^{21}$, que teria prejudicado economicamente o Brasil.

$\mathrm{Na}$ esteira do fechamento da exposição no início de setembro de 2017, vimos um vertiginoso aumento de ataque a manifestações artísticas e culturais em várias partes do país: Montenegro, no Rio Grande do Sul; Campo Grande, em Mato Grosso do Sul; Belo Horizonte, Minas Gerais e no Museu de Arte Moderna, em São Paulo. Os efeitos desses ataques ainda são difíceis de mensurar, ainda mais por nós que vivemos e trabalhamos intensamente com arte e educação. No âmbito deste texto específico, detenho-me na discussão de duas imagens fartamente divulgadas tanto pelos detratores da exposição "QueerMuseu" quanto por seus defensores e, que envolvem, diretamente, questões de gênero e sexualidade, poder e resistência. São as imagens que justificariam, segundo seus acusadores das redes sociais e de processos judiciais impetrados, a incitação de pedofilia e zoofilia e a corrupção da infância relacionadas a essas imagens. Vale lembrar que a grande maioria das pessoas que atacou a referida exposição não a viu, mas aderiu passionalmente à interpretação moralista e descontextualizada de algumas das imagens disseminadas agressivamente através de diferentes redes sociais. Considero que tais imagens são, ao contrário das interpretações apressadas feitas sobre elas, estratégias poderosas de resistência aos modos de subjetivação de certa ordem fálica das imagens artísticas ocidentais, da qual tratávamos no início deste texto.

A série "Criança Viada" de Bel Leite fez alusão a um site em que adultos

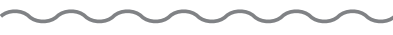

$21 \mathrm{O}$ ataque feroz às ideias progressistas por grupos neoconservadores tem sido um fenômeno crescente em várias partes do mundo, como sublinha Klein (2017), marcado, por exemplo, pela ascensão do multibilionário Donald Trump na presidência dos Estados Unidos ou pela emergência de partidos neonazistas e de ultradireita na Europa. No Brasil, com a eleição do atual presidente Jair Bolsonaro em 2018, os ideais da extrema-direita tm encontrado terreno fértil no país. 
gays e lésbicas eram convidados a enviar imagens de si mesmos quando crianças, em poses afeminadas ou masculinizadas, já desviadas dos padrões esperados para meninas e meninas. Trata-se de expor, com certa ironia, a dor e a alegria de se sentir diferente em uma fase da vida em que mais queremos e precisamos ser aceitos, que é a nossa infância. Quanto sofrimento inexplicável sofre uma criança que não entende o preconceito e a intolerância em relação ao seu modo de estar no mundo? O site sofreu inúmeros ataques, foi retomado depois da polêmica envolvendo a exposição e a obra de Bel Leite e agora encontra-se indisponível. Em outubro de 2017, um texto no site enfatizava: Nossa sexualidade está em nós desde o primeiro momento de vida - Freud explica -, mas ela se manifesta de maneira diferente em cada fase. A gente vive em um mundo que aplaude qualquer demonstração de masculinidade tóxica que venha de uma criança, mas quer apagar qualquer toque de feminilidade que um menino possa demonstrar. Fica claro que o ódio é pelo feminino, né?

O que incomoda tanto em obras que apresentam uma infância fora dos padrões heteronormativos? As obras Travesti da lambada e deusa das águas e Adriano bafônica e Luiz França She-há (ambas de 2013), tratam com humor e ironia de uma infância invisibilizada, colocando-a sob os holofotes de uma imagem artística. Em entrevista sobre a censura inesperada à exposição e a sua obra, a artista Bel Leite contesta:

A linguagem da pintura também nos insere na História com orgulho e força, diante de uma sociedade que nos quer invisíveis. Nós, LGBT, já fomos crianças. Esse assunto incomoda porque nós nunca viramos LGBT, nós sempre fomos. Todos nós devemos cuidar das crianças, não reprimir a identidade dela nem seu modo de ser no mundo, isso é muito grave (Veja mais em https://entretenimento. uol.com.br/noticias/redacao/2017/09/12/nos-lgbt-ja-fomos-criancas-esse-assunto-incomoda-diz-artista-acusada-de-pedofilia.htm?cmpid=copiaecola)

Qual a maior violência aqui? Expor as diferentes formas de viver a infância ou negar essa discussão, promovendo uma censura desmedida a essas imagens? Por que imagens como essas seriam agressivas à infância ou seriam uma forma de incitar o sexo com crianças - a condenável pedofilia - ou uma precoce sexualidade infantil?

Em relação ao trabalho de Adriana Varejão, Cena de interior II, um dos mais atacados e descontextualizados pelos seus detratores nas redes sociais, vale conhecer um pouco melhor da artista e seu trabalho. O trabalho em questão faz parte da série Terra Incógnita, em que a artista explora a cultura brasileira, em especial as representações do período colonial, expondo suas vísceras, hipocrisias e jogos de poder e violência. Um texto de Lilia Schwarcz (2017) é preciso em sua descrição e análise: 
Convido, pois, para um corpo a corpo com esse trabalho. A textura da tela produz uma espécie de ilusão visual, como se estivéssemos diante de um papel de arroz, material muito utilizado em antigas gravuras, sobretudo, orientais. Nelas, o tempo se escreve no material, destacando-se o amarelado da coloração, bem como suas imperfeições. E nesse caso é a tela que vira papel e documento. Mais ainda, o quadro mostra como os jogos sexuais, sejam eles solitários, a dois ou em grupos, não têm tempo, regra, local ou prazo de validade. Também há na obra uma janela para pensarmos em relações consentidas e outras marcadas pela violência e por processos de humilhação. Lá estão casais bem constituídos, arranjos de gênero distintos, bem como registros de misturas entre raças, povos e animais. Existem também referências à cultura do estupro que vigorou abertamente durante o período da escravidão, mas não se limitou a ele, e uma representação de práticas que da alcova escura e escondida, de um vergonhoso segundo plano, aqui ganham o centro da cena e protagonismo. Enfim, Adriana atua como "escavadora" dessas histórias plurais da sexualidade, dos desejos, das performances de gênero e de seus jogos; práticas milenares e que nos fazem, a todos, humanos (Disponível em: https://www.nexojornal.com.br/colunistas/2017/A-obra-de-Adriana-Varej\%C3\%A3o-e-nossa-Cena-de-Interior).

A artista escava, expõe, transfigura, choca, carnavaliza. Suas obras anunciam que, de algum modo, na raiz de uma celebrada diversidade e multiculturalidade brasileira, há uma cultura de estupro e violência de mulheres negras e indígenas pouco vista, negada, ocultada, subsumida em meio às letras oficiais da história, repletas de homens brancos importantes, tratados e grandes documentos. Como pontua Carneiro (2019, p. 313), "a violência sexual colonial é, também, o 'cimento' de todas as hierarquias de gênero e raça presentes em nossas sociedades". Há aqui também jogos de poder e resistência. Quando se quer regular o que se pode dizer e o que se pode ver sobre práticas sexuais no campo da arte, remontamos, no mínimo, ao século XVII, época a qual Foucault identifica como o início de uma período de repressão próprio das sociedades chamadas burguesas, em que seria preciso, em relação ao sexo, "controlar sua livre circulação no discurso, bani-lo das coisas ditas e extinguir as palavras que o tornam presente de maneira demasiado sensível" (FOUCAULT, 1999, p.21). Ao mesmo tempo que o discurso é interditado, mais ainda ele é incitado. Nunca se falou tanto sobre zoofilia, por exemplo, como no período desses acontecimentos no Brasil.

Por que tais imagens envolvendo gênero e sexualidade tornaram-se intoleráveis para algumas pessoas? Por que tanto medo de que as imagens contagiem, corrompam, desconstruam as verdades que acreditamos? 


\section{Em tempos de \#fiqueemcasa, a invisibilidade da violência doméstica}

Três anos mais tarde, ainda sentimos os efeitos dos acontecimentos de 2017 nos cenários da arte e da educação. Em 2020, estamos em meio a uma pandemia por causa de um vírus, um novo coronavírus (SARS-CoV-2) que causa a doença Covid 19, que pode assemelhar-se a uma gripe comum, mas também pode ser fatal. O desfecho dessa pandemia ainda é uma incógnita, mas o alcance mundial em uma proporção vertiginosa já acirrou uma grave crise econômica na maioria dos países do mundo e um abismo educacional sem precedentes ${ }^{22}$. O confinamento em massa, obrigatório ou compulsório, a depender da estratégia adotada por cada país, fechou escolas e universidades por muito tempo. Milhões de crianças e jovens sem aula ou com aulas remotas em casa ao redor do mundo. No entanto, é importante perguntar: que casa? Quem pode aderir rapidamente e confortavelmente ao imperativo \#fiqueemcasa? A que as crianças estão expostas ficando em casa? E as mulheres, personagens que ocupam a casa há tanto tempo, trabalhando para sua própria família ou para família de outros?

Os índices de violência doméstica aumentaram durante a pandemia global, gerando o que tem se chamado de uma "pandemia invisível", conforme declaração de Phumzile Mlambo-Ngcuka, diretora executiva da ONU Mulheres e vice-secretária geral das Nações Unidas ${ }^{23}$. O confinamento aumenta a tensão e a preocupação com segurança, saúde e dinheiro e, consequentemente, estimula o isolamento de mulheres e crianças com parceiros e pais violentos, afastando-os das pessoas e dos recursos que podem ajudá-los, como as escolas, tanto tempo fechadas. Como afirma a diretora executiva da ONU Mulheres: "é uma tempestade perfeita para controlar o comportamento violento a portas fechadas".

Podemos tratar dessas questões a partir de algumas situações emblemáticas deste período. Em abril de 2020, uma mulher escreveu um pedido de socorro com batom em uma toalha e jogou pela janela: "SOS AP 203"24. Uma toalha comum, dessas que usamos todos os dias. Um batom, um artefato de embelezamento tão simples, ordinário, cotidiano. Objetos que se tornam armas em uma batalha in-

22 Em setembro de 2020, os dados atualizados sobre a pandemia são os seguintes: NO MUNDO - Casos: 31.505.761 - Óbitos: 969.518; NO BRASIL - Casos: 4.597.438 - Óbitos: 138.210. Fonte: https://dadoscoronavirus.dasa.com.br/ Acesso em 24 de setembro de 2020.

23 Ver mais em: http://www.onumulheres.org.br/noticias/violencia-contra-as-mulheres-e-meninas-e-pandemia-invisivel-afirma-diretora-executiva-da-onu-mulheres/ Acesso em 04 de setembro de 2020.

24 Mulher vítima de violência escreve pedido de socorro com batom em toalha e joga pela varanda em SC: https://g1.globo.com/sc/santa-catarina/noticia/2020/04/20/mulher-vitima-de-violencia-escreve-pedido-de-socorro-com-batom-em-toalha-e-joga-pela-varanda-em-sc.ghtml Acesso em 04 de setembro de 2020. 
glória, em um ato de desespero. Uma performance invisível de muitas mulheres. Nem todas tiveram tempo de acenar com uma toalha, nem todas foram ouvidas. A violência sutil e carregada de uma toalha escrita com batom expõe a desigualdade das condições de existência, marcada por gênero, sexualidade, raça, etnia, geração, classe social. Quem é capaz de ouvir os gritos de uma casa e de seus habitantes? E se ouvimos, o que somos capazes de fazer?

Algumas mulheres artistas ouvem, sentem, expõem-se e gritam. E cada vez mais, as suas vozes são diversas e irreconciliáveis com os feminismos (ou mesmo femininos) tradicionais. As artistas Regina Parra, Panmela Castro, Elina Chauvet e Priscila Rezende, por exemplo, nos provocam a pensar fora de nossos lugares habituais e já conformados ${ }^{25}$.

"Por que tremes, mulher?", a pergunta é o verso de um poema de Castro Alves sobre uma mulher escravizada que tem medo de que seu filho seja vendido. A artista brasileira Regina Parra recupera o verso e escancara nessa obra o modo com o qual a violência racial e de gênero é marca da história do Brasil há muito tempo. Quantas mulheres ainda tremem por seus filhos? Quantas mães negras, em especial, da periferia das maiores cidades brasileiras, temem que seus filhos não voltem para casa?

Panmela Castro cria performances a partir de suas experiências pessoais com violência de gênero, como em "Feminicídio" em que vestidos brancos manchados de vermelho ocupam lugares públicos. A violência exposta em praça pública também é o mote da artista mexicana Elina Chauvet com a sua instalação "Zapatos Rojos". Realizada em vários países desde 2009, a instalação, com sapatos femininos vermelhos em espaços públicos de diferentes cidades, faz lembrar que a dor da violência contra as mulheres continua fazendo parte do nosso presente. Ainda em praça pública, Priscila Rezende expõe, de forma aguda, a violência contra as mulheres negras na sua performance "Bombril". O cabelo da própria artista, uma mulher negra, é usado para lavar panelas na frente de todos. A mulher negra aqui deixa de ser objeto de um discurso pejorativo e naturalizado, para colocar-se como protagonista de sua própria narrativa.

Violência doméstica, violência de gênero, violência patriarcal, violência racial, violência colonial: várias nomeações que se desdobram em experiências expostas de forma contundente por essas artistas. São algumas práticas artísticas criadas a partir de "realidades estremecedoras" (ALIAGA, 2010, p. 515). As vidas encenadas por elas misturam-se às nossas. Com elas, recriamos nossas expecta-

25 Para saber mais sobre essas artistas e as obras citadas, conferir os sites das artistas: http://www.reginaparra. com.br/por-que-tremes-mulher; https://panmelacastro.com/feminicidio-feminicide; https://www.fundacaobienal.art.br/bienal-12-obras/Zapatos-Rojos; https://www.fundacaobienal.art.br/bienal-12-obras/Bombril 
tivas, nossos mitos, nossas crenças, nossas dúvidas e de tantas outras mulheres e homens de todos os seus espectros de identidade que já nos precederam e conosco convivem.

Ainda há que se pensar sobre as noções de mulher, de feminino e feminismos que estão em jogo em torno dessas práticas artísticas e seus efeitos. Mesmo em meio às representações e discursos feministas criados por mulheres, pode também haver traços de violência. O que dizer, por exemplo, sobre o ar de superioridade do feminismo branco em torno do mito da fragilidade feminina? Sueli Carneiro alerta:

\begin{abstract}
Nós, mulheres negras, fazemos parte de um contingente de mulheres, provavelmente majoritário, que nunca reconheceram em si mesmas esse mito, porque nunca fomos tratadas como frágeis. Fazemos parte de um contingente de mulheres que trabalharam durante séculos como escravas nas lavouras ou nas ruas, como vendedoras, quituteiras, prostitutas... Mulheres que não entenderam nada quando as feministas disseram que as mulheres deveriam ganhar as ruas e trabalhar. Fazemos parte de um contingente de mulheres com identidade de objeto. Ontem, a serviço de frágeis sinhazinhas e de senhores de engenho tarados (CARNEIRO, 2019, p.314).
\end{abstract}

Em meio à pandemia, todas essas discussões confluem e tornam-se, cada vez mais, urgentes. Voltamos a mensagem desesperada da mulher de Santa Catarina em uma toalha com batom. "Ficar em casa não é o mesmo que calar-te em casa" expressa um dos grafittes do coletivo "Mujeres Creando", da Bolívia. Ainda assinalam as faixas empunhadas pelo coletivo feminista: "O machismo é a única pandemia que não está em quarentena" ${ }^{26}$.

Mas o que todas essas questões têm a ver com arte e educação ou arte na escola?

\title{
Arte, resistência e novas paisagens do possível
}

Acredito, como Rancière, que as imagens da arte "contribuem para desenhar configurações novas do visível, do dizível e do pensável e, por isso mesmo, uma paisagem nova do possível. Mas o fazem com a condição de não antecipar seu sentido e seu efeito" (RANCIÈRE, 2012, p.100).

26 Ver mais em http://mujerescreando.org/el-machismo-es-la-unica-pandemia-que-no-esta-en-cuarentena/ Acesso em setembro de 2020. 
O fascínio das artes, a meu ver, reside justamente na capacidade de mover modos de pensar, expor pensamentos divergentes do senso comum, criar novos polos de resistência às relações de poder-saber, produzir rupturas nas superfícies lisas do cotidiano, sem que, para isso, precise dar soluções, apresentar uma mensagem edificante ou moralizante. É desse modo que o grupo ARTEVERSA ${ }^{27}$ tem pensado a partir de obras e proposições de artistas sobre educação e formação. Aprendemos muito com as estratégias de artistas que "se propõem mudar os referenciais do que é visível e enunciável, mostrar o que não era visto, mostrar de outro jeito o que não era facilmente visto, correlacionar o que não estava correlacionado, com o objetivo de produzir rupturas no tecido sensível das percepções e na dinâmica dos afetos" (RANCIĖRE, 2012, p.64). Precisamos de mais arte que produza dissensos, que produza relações novas com o mundo, que modifique nossa reinscrição na existência, que se oponha a adaptações miméticas de uma suposta realidade ou de produções artísticas de finalidade moralizante. Artistas como as citadas até aqui e outras como Catherine Opie, Zanele Muholi, Rosana Paulino, Shirin Neshat, Carrie Mae Weems, Jota Mombaça ou o grupo Guerrilla Girls, por exemplo, têm produzido imagens e ações poéticas provocativas aos nossos modos de ver e pensar sobre a relação entre arte, gênero, raça e sexualidade ${ }^{28}$. Voltando às questões iniciais deste texto, o que o campo de arte e educação pode aprender com essas imagens e produções artísticas e com o debate contemporâneo sobre gênero e sexualidade?

Ainda que as interdições estejam presentes e constantes, não há mais como voltar. A eliminação da palavra gênero de documentos curriculares ou a demonização de uma suposta discussão de gênero em torno da nomeada "ideologia de gênero" (JUNQUEIRA, 2018) não vão impedir que corpos vibrem, que a sexualidade transborde e que a diversidade de gênero transite, mesmo nas mais "inocentes" e contemplativas aulas de artes, queiramos ou não. Podemos aliar-nos a Huerta $(2016$, p. 2) que aposta em uma educação artística como motor de mudança social, encaminhando esforços até "uma maior aceitação da diversidade sexual nas aulas". Ou, tensionando um pouco mais, apostar em uma educação que reivindique práticas artísticas que "emudeçam a experiência estética idealista baseada na contemplação desinteressada por outra intermitente, dispersa e que

27 O ARTEVERSA - Grupo de estudo e pesquisa em arte e docência (UFRGS/CNPQ) foi criado em 2015 e, desde então, vem problematizando de vários modos as possibilidades entre arte contemporânea, educação e docência. O site do grupo é: www.ufrgs.br/arteversa

28 A revista Select, revista de arte e cultura editada em São Paulo, publicou um número especial sobre gênero em 2018 (edição\#38), em que procura desestabilizar as noções mais comuns sobre o tema: “é no sentido de desorientar, desobedecer e desestabilizar esse estado das coisas que atuam os artistas, coletivos, curadores, críticos, filósofos, pesquisadores, jornalistas, performers, ativistas transgênero, queer e feministas aqui reunidos" (Editorial Não se nasce mulher, torna-se, Revista Select, mar/abr/mai 2018). 
reclama como imprescindível uma tomada de posição" (MARTINEZ, 2012, p. 170). Já é tempo de tomarmos uma posição em direção a uma articulação entre arte e educação que seja capaz de produzir uma nova imaginação política.

Talvez essa seja a tarefa mais urgente a que nós, que nos dedicamos à arte e educação, precisamos nos comprometer: produzir, buscar, analisar, compartilhar imagens que produzam dissensos sobre gênero, sexualidade e violência, e novas estratégias de resistência aos modos de subjetivação que nos assolam, buscando, incansavelmente, novas paisagens do possível.

\section{Referências:}

ALIAGA, Juan Vicente. Orden fálico: 66androcentrismo e violencia de género en las prácticas artísticas del siglo XX. Madrid: Akal, 2010.

BARROS, Roberta. Elogio ao toque ou como falar de arte feminista à brasileira. Rio de Janeiro: Editora do autor, 2016.

CARNEIRO, Sueli. Enegrecer o feminismo: a situação da mulher negra na América Latina a partir de uma perspectiva de gênero. In: HOLLANDA, Heloísa Buarque de (org.). Pensamento feminista: conceitos fundamentais. Rio de Janeiro: Bazar do tempo, 2019, p. 313-321.

COUTINHO, Andrea Senra; LOPONTE, Luciana Gruppelli. Artes visuais e feminismos: implicações pedagógicas. Revista Estudos Feministas (UFSC. Impresso), v. 23, p. 181-190, 2015.

CULT - Revista Brasileira de Cultura. Dossiê Arte sob coerção: moralismo privado no espaço público. São Paulo, n. 230, dez. 2017.

CYPRIANO, Fabio. Arte acovardada. Bravo! - panorama. São Paulo: Bravo Editorial: São Paulo, 2018. p. 75-91.

DIAS, Taís Ritter. Ensino de arte e feminismos: urdiduras entre relações de poder e resistências. Dissertação (Mestrado em Educação) - Universidade Federal do Rio Grande do Sul, 2017.

FOUCAULT, Michel. História da sexualidade: a vontade de saber. Rio de Janeiro: Graal, 1999.

HUERTA, Ricard. Transeducar: arte, docencia y derechos LGBT. Barcelona, Madrid: Egales, 2016.

JUNQUEIRA, Rogério Diniz. A invenção da “ideologia de gênero": a emergência 
de um cenário político-discursivo e a elaboração de uma retórica reacionária antigênero. Rev. psicol. polít., São Paulo, v. 18, n. 43, p. 449-502, dez. 2018 . Disponível em http://pepsic.bvsalud.org/scielo.php?script=sci_arttext\&pid=S1519$-549 X 2018000300004 \& \operatorname{lng}=$ pt\&nrm=iso . acessos em 24 set. 2020

KLEIN, Naomi. Não basta dizer não: resistir à nova política de choque e conquistar o mundo do qual precisamos. Rio de Janeiro: Bertrand Brasil, 2017.

LOPONTE, Luciana Gruppelli. Artes visuais, feminismos, gênero e educação: discursos silenciados. Universitas Humanistica, v. 79, p. 143-163, 2015.

LOPONTE, Luciana Gruppelli. Gênero, visualidade e arte: temas contemporâneos para educação. In: ICLE, Gilberto (org.). Pedagogia da arte: entre-lugares da criação. Porto Alegre: UFRGS, 2010. p. 149-163.

LOPONTE, Luciana Gruppelli. Gênero, educação e docência nas artes visuais. Educação \& Realidade, n. 30, v. 2, p. 243 - 259, jul/dez 2005.

MARTINEZ, Pablo. De qué otra cosa podríamos hablar...hoy? IN: AZNAR, Yayo, MARTÍNEZ, Pablo (eds). Arte actual: lecturas para un espectador inquieto. Madrid: Centro de Arte Dos de Mayo, 2012.

MAYAYO, Patricia. Historias de mujeres, historias del arte. Madrid: Catedra, 2003.

NERI, Louise, HERKENHOFF, Paulo (orgs.). Adriana Varejão. São Paulo: O autor, 2001.

POLLOCK, Griselda. A modernidade e os espaços de feminilidade. In: MACEDO, Ana Gabriela, RAYNER, Francesca. Gênero, cultura visual e performance: antologia crítica. Húmus/Universidade do Minho: Famalicão, 2011.

POLLOCK, Griselda. Vision and difference: feminism, femininity and the histories of art. London: Routledge, 1988.

RANCIÈRE, Jacques. O espectador emancipado. São Paulo: Martins Fontes, 2012.

SCHWARCZ, Lilia. A obra de Adriana Varejão e nossa 'Cena de Interior', NEXO, set. 2017. Disponível em: https://www.nexojornal.com.br/colunistas/2017/A-obra-de-Adriana-Varej\%C3\%A3o-e-nossa-Cena-de-Interior

SELECT, Revista de Arte e Cultura Contemporânea, São Paulo, n. 38, mar/abr/mai 2018.

VELOSO, Juliana de Lima. Fendas: pensar corpo, gênero e sexualidade com arte e educação. Dissertação de mestrado em educação. UFRGS, 2019. 